\title{
Study on Preparation Technology and Physical Fingerprint of Chuilian Jianpi Granules Based on QbD
}

\author{
Guangjiao Zhou $\mathbb{D}^{1,2}$ Xiao-Wei Li, ${ }^{3}$ Jin-Cai Li, ${ }^{1}$ and Xue-Hua Feng ${ }^{4}$ \\ ${ }^{1}$ Bozhou Chinese Medicine Institute, Anhui Academy of Chinese Medicine, Bozhou 236800, China \\ ${ }^{2}$ Bozhou Vocational and Technical College, Bozhou 236800, China \\ ${ }^{3}$ Meng Cheng Hospital of Chinese Medicine, Bozhou 236800, China \\ ${ }^{4}$ Anhui Xinhua University, Hefei 230088, China \\ Correspondence should be addressed to Guangjiao Zhou; 403621620@qq.com
}

Received 30 March 2021; Accepted 21 August 2021; Published 30 September 2021

Academic Editor: Ali Akgül

Copyright $\odot 2021$ Guangjiao Zhou et al. This is an open access article distributed under the Creative Commons Attribution License, which permits unrestricted use, distribution, and reproduction in any medium, provided the original work is properly cited.

\begin{abstract}
Objective. To optimize the preparation formula and technology of Chuilian Jianpi granules. Methods. The formulation and preparation process were optimized by single factor experiment and response surface analysis, with the molding rate, hygroscopicity, and fluidity of particles as the comprehensive evaluation indexes, and the comprehensive score as the response value according to different weights. To further evaluate the stability and feasibility of the preparation formulation and technology, the physical fingerprint of the granules was constructed by seven indicators including particle tap density, bulk density, hygroscopicity, water content, angle of repose, Hausner ratio, and relative homogeneity index. Results. The optimum formula conditions of Chuilian Jianpi granules were as follows: the dosage ratio of drug to adjuvant was $1: 0.8$, lactose:mannitol $=1.5: 1$, and the amount of wetting agent ( $90 \%$ ethanol) was $25 \%$ of the granules, with high-speed stirring granulation. The similarity of the physical fingerprints of the 10 batches of Chuilian Jianpi granules was high, which is above $98.5 \%$. Conclusion. The optimized preparation technology was stable and feasible, which can provide reference for the development of Chuilian Jianpi granules and other Chinese medicine granules.
\end{abstract}

\section{Introduction}

The Chuliani Jianpi granule is a prescription developed by the Mengcheng County Hospital of Traditional Chinese Medicine of Anhui Province based on modern pharmacological studies. The Mengcheng County Hospital has exclusive ownership of the prescription. This prescription is composed of 17 traditional Chinese medicines, including Spreading Hedyotis Herba, Sedi Herba, Scutellariae Barbatae Herba, Polygoni Cuspidati Rhizoma Et Radix, Pheretima, Poria, Galli Gigerii Endothelium Corneum, Crataegi Fructus, Citri Sarcodactylis Fructus, Aurantii Fructus, Moutan Cortex, Rhei Radix Et Rhizoma, Artemisiae Scopariae Herba, Schisandrae Chinensis Fructus, Glycyrrhizae Radix Et Rhizoma, Astragali Radix, and Coptidis Rhizoma. Years of clinical verification by the Mengcheng County Hospital of Traditional Chinese Medicine proved its functions of clearing away heat and toxic materials, soothing liver, and regulating $\mathrm{qi}$, as well as fortifying the spleen and disinhibiting dampness. It is mainly used for chest pain caused by dampness and heat in the liver and gallbladder, mouth pain, nausea and vomiting, dysuria or yellowish urine, yellowing of body and eyes, chronic hepatitis, and ascites due to cirrhosis. However, in clinical practice, this prescription shows poor stability and portability. Our research group developed it into "Chuilian Jianpi granules", which featured portability and stability, thus better serving the patients. Focusing on the quality by design $(\mathrm{QbD})$, this paper adopted the molding rate, moisture absorption rate, and fluidity of granules as evaluation indexes [1-6]. The team optimized the preparation formula and production procedures of Chuilian Jianpi granules by single-factor-based Box-Behnken experiment. The physical fingerprint of the particles was established based on physical properties such as stacking, 
fluidity, stability, and uniformity [7-10]. The particles were fully evaluated to ensure the stable and controllable quality of the particles, thus providing experimental data for the preparation, production, and quality control of the prescription.

\section{Testing Instruments and Materials}

2.1. Main Experimental Instruments. GHL-150 high-speed stirring granulator (Changzhou Subang Drying Equipment Co. Ltd.) and RXH-5-C hot air circulation drying box (Shanghai Tianxiang Pharmaceutical Machinery) were used in this study.

2.2. Materials. Seventeen kinds of decoction pieces, such as Spreading Hedyotis Herba, Sedi Herba, Scutellariae Barbatae Herba, Polygoni Cuspidati Rhizoma Et Radix, Pheretima, Poria, Galli Gigerii Endothelium Corneum, Crataegi Fructus, Citri Sarcodactylis Fructus, Aurantii Fructus, Moutan Cortex, Rhei Radix Et Rhizoma, Artemisiae Scopariae Herba, Schisandrae Chinensis Fructus, Glycyrrhizae Radix Et Rhizoma, Astragali Radix, and Coptidis Rhizoma, were purchased from Yonggang Decoction Pieces Factory in Bozhou of Anhui Province. Chen Na, Associate Professor of Bozhou Vocational and Technical College Pharmacy School, confirmed that the Spreading Hedyotis Herba conforms to the requirements specified in the 2008 edition of Shanghai Chinese Herbal Pieces Processing Standard. The rest also meet the requirements specified in the first edition of Chinese Pharmacopoeia, 2020. Mannitol and lactose (Anhui Shanhe Pharmaceutical Accessories Co., Ltd.) and ethanol (Xinxiang Xianfeng Pharmaceutical New Materials Co., Ltd.) were analytically pure, and purified water was made by the laboratory.

\section{Method and Result}

3.1. Preparation of Chuilian Jianpi Granules. According to previous experimental studies, 17 kinds of Chinese herbal pieces, including Spreading Hedyotis Herba, Sedi Herba, Sophorae Tonkinensis Radix Et Rhizoma, Scutellariae Barbatae Herba, Polygoni Cuspidati Rhizoma Et Radix, Pheretima, Poria, Galli Gigerii Endothelium Corneum, Crataegi Fructus, Citri Sarcodactylis Fructus, Aurantii Fructus, Moutan Cortex, Rhei Radix Et Rhizoma, Artemisiae Scopariae Herba, and Schisandrae Chinensis Fructus, were decocted with 10 times of water and boiled twice, with the first time lasting 1.5 hours and the second time one hour. Then, it was filtered and mixed and concentrated to a relative density of $1.15 \sim 1.25$ before being dried under reduced pressure at $80^{\circ} \mathrm{C}$ to obtain dry paste. After being crushed, it was mixed with 2 times of auxiliary materials (lactose: mannitol $=1.5: 1)$. Then, the $90 \%$ ethanol was used as wetting agent in an amount of $25 \%$ of the total material. Then, the mixture was stirred at high speed to make wet granules and dried [10-12].

3.2. Granule Evaluation. In the pre-experiment, the lactose and mannitol were found to be ideal diluents to dissolve granules. Therefore, factors like the molding rate, moisture absorption, and fluidity instead of the solubility were taken as indicators for evaluation. The granules were evaluated according to the weight coefficients of 40, 30, and 30, with a full score of 100 points. The final score $=$ molding rate $\times 40 /$ maximum molding rate + minimum moisture absorption rate $\times 30$ / moisture absorption rate + minimum angle of repose $\times 30$ / angle of repose [13-16]. Based on the physical properties of particles, the physical fingerprint of particles is constructed with four primary properties of stacking, stability, fluidity, and uniformity and seven secondary parameters of tap density, bulk density, hygroscopicity, water content, angle of repose, Hausner ratio, and relative homogeneity $[9,10]$. The stacking property of particles is characterized by tap density and bulk density, the stability featured by hygroscopicity and water content, the fluidity of particles by repose angle and Hausner ratio, and the uniformity of particles by relative homogeneity. The measurement of each indicator is as follows.

3.2.1. Molding Rate. The dried granules were weighed and marked as $W_{1}$, which then passed through No. 1 sieve and No. 5 sieve, respectively. Granules that passed through No. 1 sieve but got stuck in No. 5 sieve were collected, weighed, and marked as $W_{2}$. The forming rate $=W_{2}{ }^{*} 100 \% / W_{1}$.

3.2.2. Bulk Density. Five grams of Chuilian Jianpi granules were taken and marked as $\mathrm{W}$ and then slowly added into a dry and clean measuring cylinder of $25 \mathrm{~mL}$. The volume $\left(V_{\mathrm{a}}\right)$ of granules was read, and the bulk density was calculated according to the following formula: bulk density $=W / V_{\mathrm{a}}$.

3.2.3. Tap Density. The measuring cylinder filled with particles was vibrated up and down for 200 times at a frequency of $2 \mathrm{~s} /$ time. The volume $\left(V_{\mathrm{C}}\right)$ of particles was read, and the tap density of particles was calculated according to the following formula: tap density $=W / V_{\mathrm{C}}$.

3.2.4. Moisture Absorption [16]. Three grams of particles dried to constant weight were accurately weighed and marked as $m_{1}$. Then, they were placed in a closed environment with a relative humidity of $75 \%$ and stored in a constant temperature incubator at $25^{\circ} \mathrm{C}$. 24 hours later, they were weighed and marked as $m_{2}$. The moisture absorption rate was calculated according to the following formula: moisture absorption rate $=\left(m_{1}-m_{2}\right) / m_{1} \times 100 \%$.

3.2.5. Water Content. Two grams of particles were placed in a sample tray and heated to constant weight at $105^{\circ} \mathrm{C}$. Then, a quick moisture analyzer was used to read their water content.

3.2.6. Angle of Repose. The funnel was used for determining the angle of repose, which was horizontally fixed at a height $h$ from the graph paper. The particles were slowly poured into it until the top of the particles touched the top of the funnel, and the particles formed a cone with the height $h$ and radius $r$. The angle of repose was calculated according to $\alpha=h / r$. 
3.2.7. Hausner Ratio. It was calculated based on the following formula: Hausner ratio $=$ tap density/loose density.

3.2.8. Relative Homogeneity. Based on approaches proposed by previous literatures $[4,9]$, the Chuilian Jianpi granules were screened by $24,50,65,120,180$, and 325 meshes in turn and oscillated for $5 \mathrm{~min}$, after which the mass of the granules intercepted on each screen was recorded, respectively. The relative homogeneity was calculated by taking particles trapped by screens with average pore diameters of 603,303 , 188,108 , and $83 \mu \mathrm{m}$.

3.3. Optimized Single-Factor Experiment. In the pre-experiment, it was found that the dry paste of Chuilian Jianpi recipe has a strong viscosity in the presence of water. When dextrin, starch, or their mixture is used as diluent, it is not easy to form a fixed shape in addition to its poor solubility. However, the mixture of lactose and mannitol features much greater solubility and formability $[17,18]$. Based on evaluation indicators under "Section 2.2," the effect of adjuvant ratio, lactose and mannitol ratio, wetting agent, and various dosages on the final score of Chuilian Jianpi granules was investigated.

This paper also studied the effect of adjuvant ratio (in the ratio of $0.5: 1,1: 1,1.5: 1,2: 1$, and $2.5: 1)$, lactose and mannitol (in the ratio of $0.5: 1,1: 1,1.5: 1,2: 1$, and $2.5: 1$ ), ethanol concentration of wetting agent $(60 \%, 70 \%, 80 \%$, $90 \%$, and $95 \%)$, and the dosage of wetting agent $(10 \%, 15 \%$, $20 \%, 25 \%$, and $30 \%$ ) on the performance of Chuilian Jianpi granules, as shown in Table 1.

The preparation was carried out based on the above parameters, with the value of single-factor parameter as abscissa and the overall evaluation (marked as " $Y$ ") as ordinate. The data were used to create a graph, as shown in Figure 1. In Figure 1, there is a rise in the efficiency with the ratio of adjuvant drugs increasing between $0.5: 1$ and $1.5: 1$, while there was no significant change in the efficiency when it varies between $1.5: 1$ and $2.5: 1$. With the increasing ratio of adjuvant drugs, the daily dosage of granules will go up as well. This paper took the ratio of $1: 1,1: 1$, and $2: 1$ as ideal option considering the final score and daily dosage. The efficacy increases before going down with the increase of lactose: mannitol ratio, which peaks at the ratio of $2: 1$. Therefore, the ratio of $1.5: 1,2: 1$, and $2.5: 1$ is taken as possible option. When the concentration of ethanol is $90 \%$, the efficiency is significantly higher than other concentrations. Therefore, the $90 \%$ ethanol is selected as the wetting agent for granule preparation. The efficiency of the granules also shows the trend of rise and fall with the increase of ethanol dosage, which peaked at the dosage of $25 \%$. Therefore, the dosages of $20 \%, 25 \%$, and $30 \%$ were taken as options for optimization.

\subsection{Optimization of Granulation by Response Surface Methodology}

3.4.1. Design of the Response Surface Experiment. On the basis of single-factor pre-experiment, factors including adjuvant ratio (marked as " $A$ "), lactose: mannitol (marked as " $B$ "), and ethanol consumption (marked as " $C$ ") were taken as the investigation factors. According to the principles of response surface methodology, three levels were set for the three investigation factors, which were expressed by code values $-1,0$, and 1 , as shown in Table 2 .

3.4.2. Results and Variance Analysis of the Response Surface Experiment. Based on the design of the Box-Behnken experiment, the prescription was optimized with the $90 \%$ ethanol as the wetting agent. The method under "Section 3.2" was used to calculate the final score, which was taken as the response value. The analysis was done using Analysis using software and Box-Behnken response surface method. The results are shown in Tables 3 and 4. The variance analysis and multiple regression fitting were performed, with the $P<0.01$ and $R^{2}=0.9593$, indicating statistical significance of the model. The values were consistent with the predictions. The lack of fit had $P>0.05$, indicating the feasibility of the equation in preparing the Chuilian Jianpi granules. The quadratic multiple regression equation is given by

$$
Y=94.03+2.55 A+1.01 B+1.49 C+2.37 A B+2.81 A C+0.61 B C-3.09 A^{2}-4.71 B^{2}-3.91 C^{2}
$$

In the simple linear regression model, $A$ had high significance while $B$ and $C$ had no significance. For interaction terms, both $A$ and $C$ were significant. In the quadratic term, $A^{2}$ had certain significance, while $B^{2}$ and $C^{2}$ were highly significant. Other items were not significant. In conclusion, the effect of the three factors on the preparation of Chuilian Jianpi granules is ranked as follows: adjuvant ratio $(A)$ $>$ ethanol dosage $(C)>$ lactose: mannitol ratio $(B)$.

3.4.3. Analysis of Optimization by Response Surface Methodology. The 3D graph of the response surface was made based on the model and experimental results, as shown in Figure 2. The Design-Expert 11.0.4.0 software, combined with the results of the quadratic regression model, was used to determine the optimized conditions: adjuvant ratio $=1.88: 1$, lactose: mannitol $=1.66: 1$, and the proportion of ethanol at $27.45 \%$ of the total granule weight. Under this condition, the predicted value of the final score is 95.54 . To facilitate the preparation procedures, the optimal parameters were set as follows: adjuvant ratio $=2: 1$, lactose: mannitol $=1.5: 1$, and the proportion of ethanol at $25 \%$.

3.4.4. Verification of the Optimal Prescription. Three batches of Chuilian Jianpi dry paste were taken and processed into 
TABLE 1: The change conditions of single factor.

\begin{tabular}{|c|c|c|}
\hline Factor & $\begin{array}{l}\text { Single-factor change } \\
\text { condition }\end{array}$ & Other fixed conditions \\
\hline Adjuvant ratio (marked as “ $A$ ") & $\begin{array}{l}0.5: 1,1: 1,1.5: 1,2: 1 \\
2.5: 1\end{array}$ & $\begin{array}{r}\text { Lactose and mannitol ratio } \\
\text { ethan }\end{array}$ \\
\hline Lactose & $\begin{array}{l}0.5: 1,1: 1,1.5: 1,2: 1 \\
2.5: 1\end{array}$ & $\begin{array}{l}\text { Adjuvant ratio }=2: 1 \text {, ethanol concentration }=90 \% \text {, ethanol } \\
\text { dosage }=25 \%\end{array}$ \\
\hline $\begin{array}{l}\text { entration of wetting agent } \\
\left.C^{\prime \prime}\right)\end{array}$ & $60,70,80,90,95$ & $\begin{array}{l}\text { Lactose and mannitol ratio }=1.5: 1 \text {, adjuvant ratio }=2: 1 \text {, ethanol } \\
\qquad \text { dosage }=25 \%\end{array}$ \\
\hline Dosage of wetting agent (marked as “ $D$, , \%) & $10,15,20,25,30$ & $\begin{array}{l}\text { Lactose and mannitol ratio }=1.5: 1 \text {, adjuvant ratio }=2: 1 \text {, ethanol } \\
\text { concentration }=90 \%\end{array}$ \\
\hline
\end{tabular}
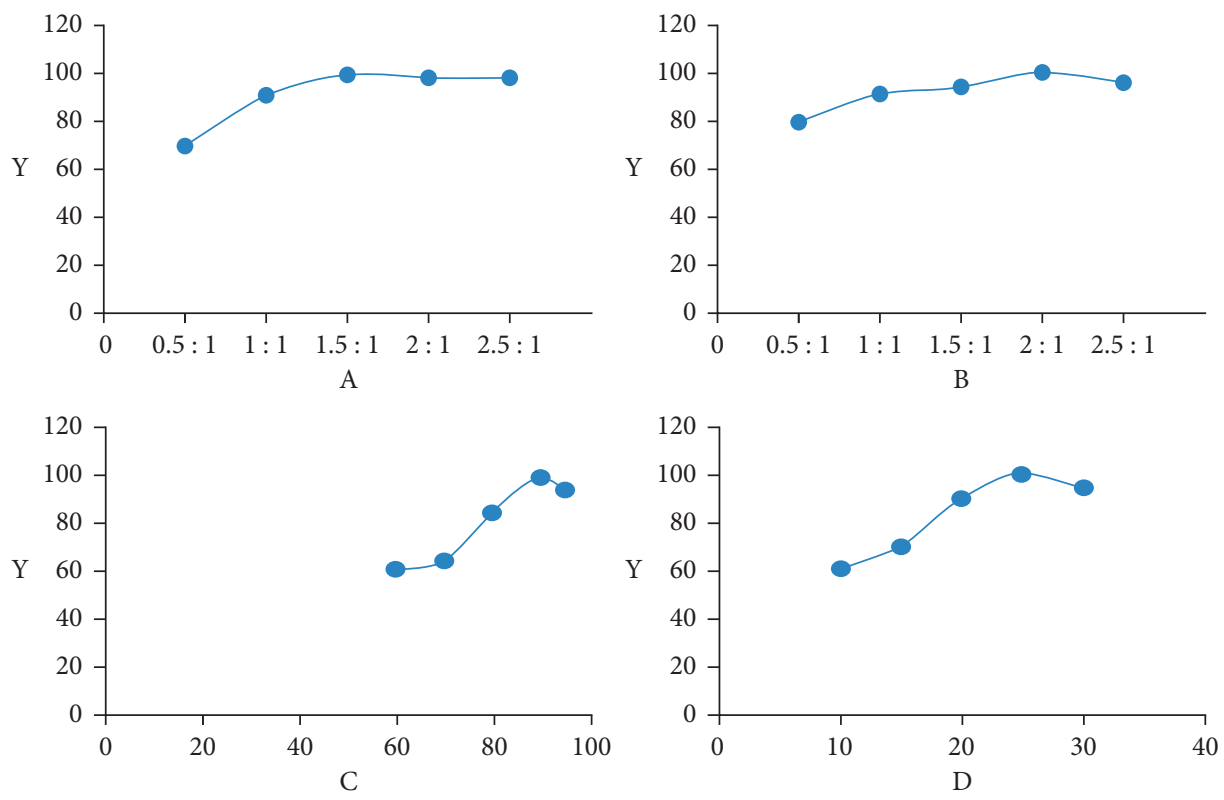

FIGURE 1: The influence of each single factor on the comprehensive score.

TABLE 2: Analysis of factors and level coding of response surface methodology.

\begin{tabular}{lccc}
\hline Adjuvant ratio $(A)$ & Lactose : mannitol $(B)$ & Dosage of ethanol $(C)(\%)$ & Level \\
\hline $1: 1$ & $1.5: 1$ & 20 & -1 \\
$1.5: 1$ & $2: 1$ & 25 & 0 \\
$2: 1$ & $2.5: 1$ & 30 & 1 \\
\hline
\end{tabular}

granules by high-speed stirring, granulating, drying, and grading based on the optimal prescription for verification. The molding rate, moisture absorption rate, and angle of repose were measured, and the results are shown in Table 5. It was found that there was no significant difference in the three batches of granules in terms of the above three factors. Also, the average value was basically consistent with predictions of the response surface, indicating the reliability and accuracy of the evaluation system and the quadratic multiple regression fitting model.

\subsection{Physical Fingerprint of Chuilian Jianpi Granules}

3.5.1. Determination and Standardization of Physical Properties of Chuilian Jianpi Granules. To verify the stability and feasibility of the optimized preparation process, 10 batches of Chuilian Jianpi granules were prepared based on the optimal prescription, with the batch numbers of 20201101, 20201102, 20201103, 20201104, 20201105, 20201106, 20201107, 20201108, 2020110, 20201110, and 20201102, respectively. According to Section 3.2, the stability and feasibility of the prescription were investigated in terms of seven physical parameters, including tap density, bulk density, moisture absorption, water content, angle of repose, Hausner ratio, and relative homogeneity, which served as the secondary indicators of the physical fingerprint. The value of each parameter was determined by the method described in Section 3.2 for the 10 batches of granules, and the results are shown in Table 6. To ensure consistency, the measured values were standardized and converted to the numerical range of $0-10$ specified by the Chinese Pharmacopoeia 2020 edition and related literatures $[4,9,19]$, as shown in Table 7. 
TABLE 3: Experimental design and results of response surface for granulation process.

\begin{tabular}{|c|c|c|c|c|c|c|c|}
\hline Number & $A$ & $B$ & $C(\%)$ & Formability (\%) & Hygroscopicity (\%) & Angle of repose & Comprehensive scores (marked as "Y”) \\
\hline 1 & 1 & 0 & 1 & 94.35 & 4.05 & 25.1 & 95.15 \\
\hline 2 & 0 & 1 & -1 & 91.52 & 5.08 & 29.21 & 84.37 \\
\hline 3 & 0 & 0 & 0 & 95.01 & 4.07 & 25.18 & 95.19 \\
\hline 4 & 0 & 0 & 0 & 94.92 & 4.26 & 24.86 & 94.38 \\
\hline 5 & 1 & -1 & 0 & 86 & 4.71 & 28.77 & 84.18 \\
\hline 6 & 0 & 0 & 0 & 95.13 & 4.28 & 24.63 & 94.64 \\
\hline 7 & 0 & -1 & -1 & 94.11 & 5.15 & 29.73 & 84.67 \\
\hline 8 & 0 & 0 & 0 & 88.04 & 3.54 & 29.31 & 91.96 \\
\hline 9 & 0 & 1 & 1 & 98.71 & 4.62 & 31.59 & 87.37 \\
\hline 10 & 0 & 0 & 0 & 96.54 & 4.26 & 25.72 & 94.00 \\
\hline 11 & -1 & -1 & 0 & 86.89 & 5.33 & 25.68 & 85.14 \\
\hline 12 & 1 & 1 & 0 & 96.73 & 4.57 & 26.01 & 92.06 \\
\hline 13 & -1 & 0 & -1 & 94.21 & 5.01 & 30.62 & 84.53 \\
\hline 14 & -1 & 0 & 1 & 88.64 & 5.07 & 29.38 & 83.09 \\
\hline 15 & 0 & -1 & 1 & 89.41 & 4.61 & 29.65 & 85.25 \\
\hline 16 & -1 & 1 & 0 & 89.32 & 5.02 & 29.41 & 83.55 \\
\hline 17 & 1 & 0 & -1 & 89.93 & 4.61 & 29.79 & 85.34 \\
\hline
\end{tabular}

TABLE 4: Analysis of variance.

\begin{tabular}{|c|c|c|c|c|c|}
\hline Source & Sum of squares & Df & Mean square & $F$ value & $P$ value \\
\hline Model & 354.14 & 9 & 39.35 & 18.33 & ${ }^{* *} 0.0005$ \\
\hline$A$ & 52.12 & 1 & 52.12 & 24.28 & 0.0017 \\
\hline$B$ & 8.22 & 1 & 8.22 & 3.83 & 0.0912 \\
\hline C & 17.85 & 1 & 17.85 & 8.31 & 0.0235 \\
\hline$A B$ & 22.42 & 1 & 22.42 & 10.44 & 0.0144 \\
\hline$A C$ & 31.64 & 1 & 31.64 & 14.74 & *0.0064 \\
\hline$B C$ & 1.46 & 1 & 1.46 & 0.68 & 0.4362 \\
\hline$A^{2}$ & 40.32 & 1 & 40.32 & 18.78 & *0.0034 \\
\hline$B^{2}$ & 93.29 & 1 & 93.29 & 43.45 & $* * 0.0003$ \\
\hline$C^{2}$ & 64.44 & 1 & 64.44 & 30.01 & ${ }^{* *} 0.0009$ \\
\hline Residual & 15.03 & 7 & 2.15 & \multirow{4}{*}{1.94} & \multirow{4}{*}{0.2653} \\
\hline Lack of fit & 8.90 & 3 & 2.97 & & \\
\hline Pure error & 6.13 & 4 & 1.53 & & \\
\hline Cor total & 369.17 & 16 & $R^{2}=0.9593$ & & \\
\hline
\end{tabular}

*Signifying salience; ${ }^{* *}$ signifying high salience.
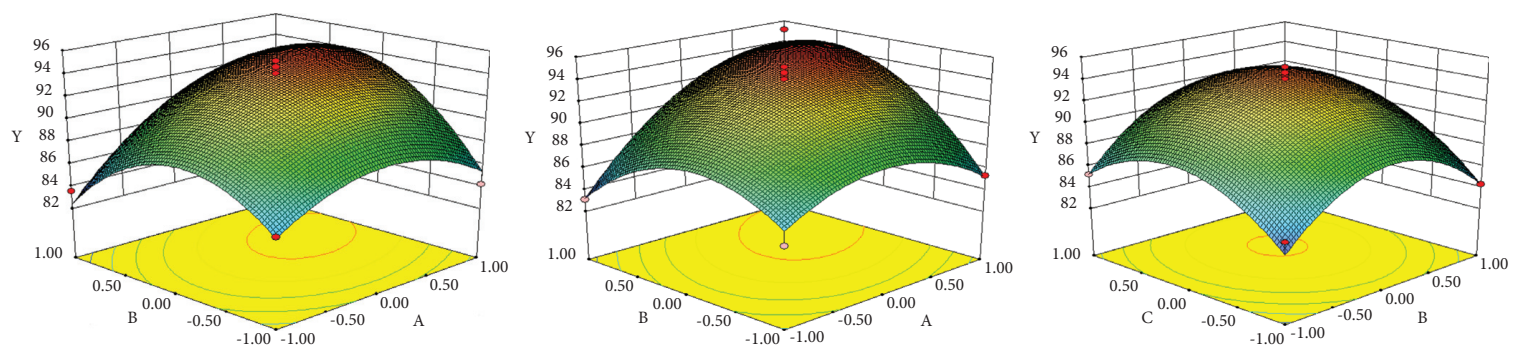

Figure 2: Response surface 3D map of each dependent variable relative to its respective variable.

TABLE 5: Results of verification $(n=3)$.

\begin{tabular}{lccc}
\hline Batch & Formability (\%) & Hygroscopicity (\%) & Angle of repose \\
\hline First batch & 94.51 & 3.69 & 26.25 \\
Second batch & 93.68 & 3.71 & 26.41 \\
Third batch & 94.01 & 3.75 & 26.65 \\
Average value & 94.07 & 3.72 & 26.44 \\
\hline
\end{tabular}


TABLE 6: The physical evaluation index results of ten batches of granules $(n=10)$.

\begin{tabular}{lccccccc}
\hline $\begin{array}{l}\text { Batch } \\
\text { number }\end{array}$ & $\begin{array}{c}\text { Tap } \\
\text { density }\end{array}$ & $\begin{array}{c}\text { Bulk } \\
\text { density }\end{array}$ & $\begin{array}{c}\text { Hygroscopicity } \\
(\%)\end{array}$ & $\begin{array}{c}\text { Water content } \\
(\%)\end{array}$ & $\begin{array}{c}\text { Hausner } \\
\text { ratio }\end{array}$ & $\begin{array}{c}\text { Angle of repose } \\
\left({ }^{\circ} \mathrm{C}\right)\end{array}$ & $\begin{array}{c}\text { Relative homogeneity } \\
\text { index }\end{array}$ \\
\hline 20201101 & 0.46 & 0.33 & 3.67 & 3.89 & 1.39 & 26.75 & 0.0096 \\
20201102 & 0.47 & 0.33 & 3.54 & 3.75 & 1.42 & 27.15 & 0.0098 \\
20201103 & 0.45 & 0.32 & 3.49 & 3.64 & 1.41 & 27.56 & 0.0102 \\
20201104 & 0.49 & 0.35 & 3.65 & 3.86 & 1.40 & 26.96 & 0.0101 \\
20201105 & 0.48 & 0.35 & 3.81 & 4.02 & 1.37 & 27.13 & 0.0096 \\
20201106 & 0.47 & 0.35 & 3.76 & 3.98 & 1.34 & 27.45 & 0.0102 \\
20201107 & 0.48 & 0.34 & 3.69 & 3.82 & 1.41 & 26.56 & 0.0095 \\
20201108 & 0.47 & 0.33 & 3.82 & 3.63 & 1.42 & 27.02 & 0.0101 \\
20201109 & 0.47 & 0.34 & 3.58 & 4.11 & 1.38 & 26.35 & 0.0097 \\
20201110 & 0.45 & 0.32 & 3.6 & 3.73 & 1.41 & 26.89 & 26.98 \\
Average & 0.47 & 0.34 & 3.66 & 3.84 & 1.40 & 20.0098 \\
value & & & & & & &
\end{tabular}

TABLE 7: Standardized conversion method of secondary physical indexes.

\begin{tabular}{lccc}
\hline Level indicators & The secondary indicators & Numerical range $(x)$ & Conversion formula \\
\hline \multirow{2}{*}{ Bulk property } & Tap density $\left(\mathrm{g} / \mathrm{mL}^{-1}\right)$ & $0 \sim 1$ & $10 x$ \\
& Bulk density $\left(\mathrm{g} / \mathrm{mL}^{-1}\right)$ & $0 \sim 1$ & $10 x$ \\
\hline \multirow{2}{*}{ Stability } & Hygroscopicity $(\%)$ & $20 \% \sim 0$ & $10-(x / 2)$ \\
& Water content $(\%)$ & $10 \% \sim 0$ & $(30-x$ \\
\hline \multirow{2}{*}{ Mobility } & Hausner ratio & $0 \sim 3$ & $10 x) / 2$ \\
& Angle of repose $\left(^{\circ}\right)$ & $50 \sim 0$ & $10-(x / 5)$ \\
\hline Uniformity & Relative homogeneity index & $0 \sim 0.02$ & $500 x$ \\
\hline
\end{tabular}

3.5.2. Establishing Physical Fingerprint of Chuilian Jianpi Granules. The values of the seven physical parameters for the 10 batches of drugs were transformed, based on which the radar charts of each batch were drawn to establish the physical fingerprint of Chuilian Jianpi granules. The average values of the converted parameters were used to draw the radar charts as the control physical fingerprint, as shown in Figure 3.

3.5.3. Similarity Analysis of Physical Fingerprint. The similarities between the physical fingerprints of the above 10 batches of Chuilian Jianpi granules and the control physical fingerprints were analyzed by the cosine method of SPSS 17.0. The closer the similarity to 1 , the more stable and uniform the product. The results showed that the physical fingerprint similarity of the 10 batches of Chuilian Jianpi granules was $99.2 \%$ and $98.9 \%$, respectively, all of which are above $98.5 \%$. The result suggests little difference in the physical properties of each batch of granules, indicating stability of the prescription.

\section{Discussion}

4.1. Preparation Method and Selection of Adjuvant Materials. Chuilian Jianpi offers a variety of options and features large total dose and a high rate of paste extraction in the presence of water. Increase in the amount of wet adjuvant materials would increase the daily dosage, which would be too strong for patients. Therefore, it is recommended to process the material into dry paste before being applied in drug production. The dry paste has strong water absorption and high viscosity when it meets water. In the preparation, high-concentration ethanol was selected as the wetting agent, and lactose and mannitol were used as diluents.

4.2. Establishment of the Granule Evaluation System. In the pre-experiment, the granules prepared under any ratio of lactose and mannitol showed good solubility. Therefore, the solubility was not taken into the single-factor evaluation and response surface optimization experiment.

4.3. The Concept of $Q b D$ and Physical Fingerprint. The principle of $\mathrm{QbD}$ emphasizes the role of procedures in ensuring product quality $[18,19]$. The traditional evaluation method based on particle forming rate and substance content can no longer fully evaluate the prescription and preparation procedures. In particular, the substance content would not cause significant changes because of the simple forming procedures. In the pre-experiment, the preparation procedure was found to have little effect on the parameters, 


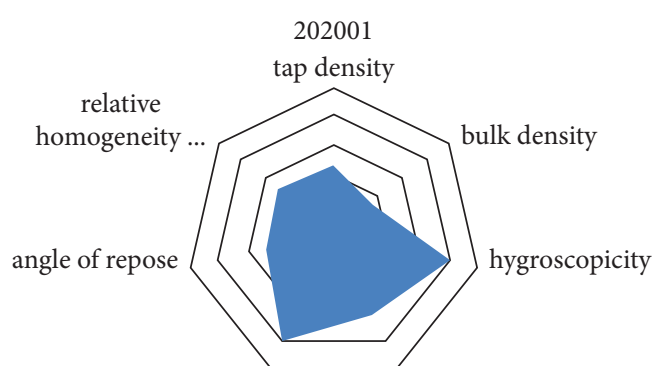

Hausner ratio loss on drying

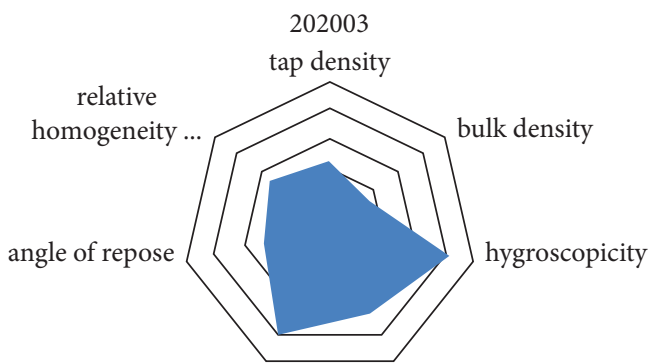

Hausner ratio

loss on drying

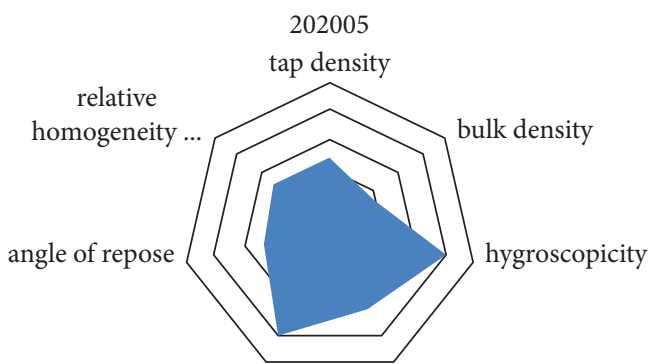

Hausner ratio loss on drying

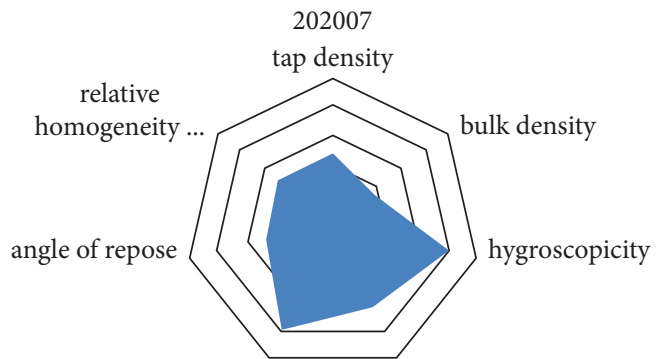

Hausner ratio

loss on drying
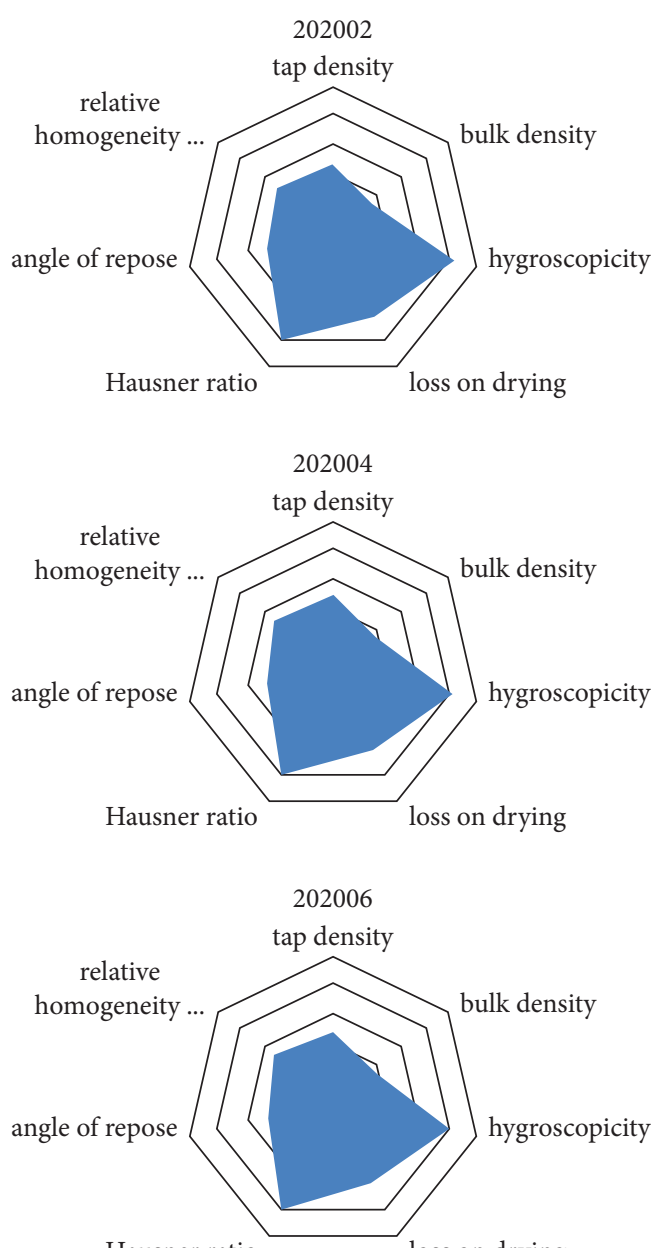

Hausner ratio loss on drying

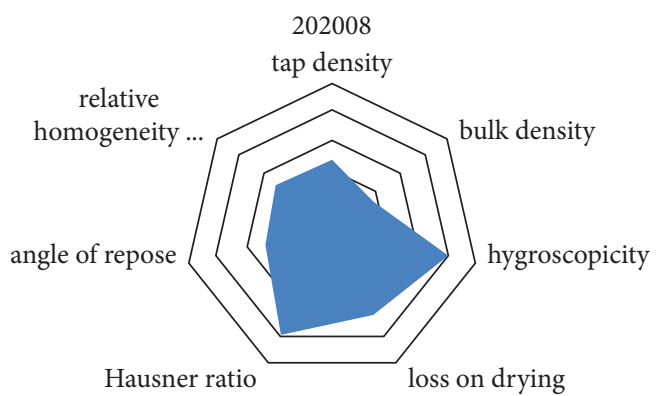

(a)

FIgURE 3: Continued. 

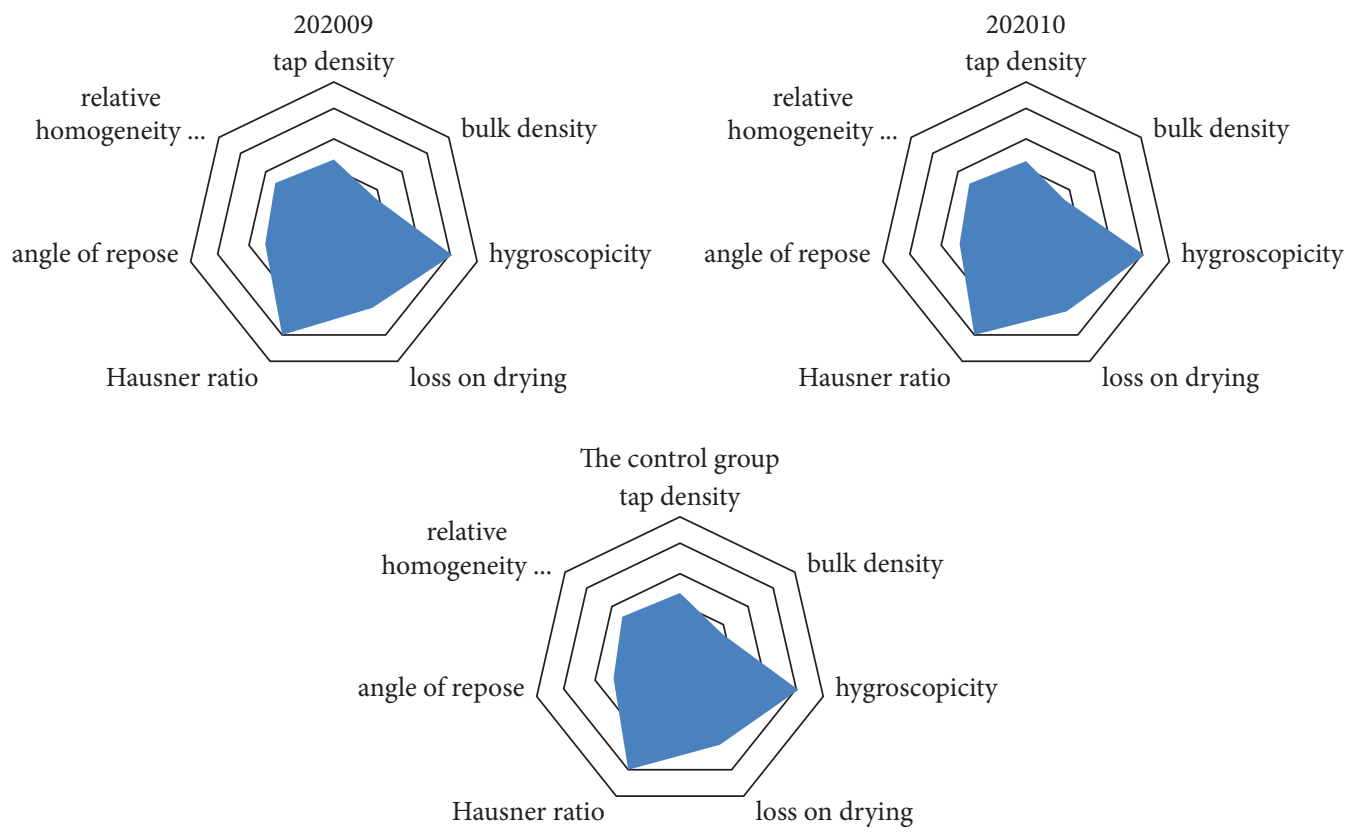

(b)

Figure 3: Physical fingerprint spectrum of Chuilian Jianpi granules.

with no significant difference in the parameters of the granule. Therefore, it was used in the evaluation of granules. In this paper, seven parameters, including tap density, bulk density, and moisture absorption, were used to establish physical fingerprint to evaluate the stability and feasibility of the preparation formula and procedures. The idea is consistent with $\mathrm{QbD}$, and therefore it is worthy of promotion.

\section{Data Availability}

The data used to support the findings of this study are available from the corresponding author upon request.

\section{Conflicts of Interest}

The authors declare that there are no conflicts of interest regarding the publication of this paper.

\section{Acknowledgments}

This study was supported by the Technical Innovation and Social Service Team of Bozhou Vocational and Technical College (no. yptd001), Key Research Project of Bozhou Institute of Traditional Chinese Medicine of Anhui Academy of Traditional Chinese Medicine (nos. ykzzd008 and ykzyb011), Key Project of Anhui Vocational Adult Education Association (no. AGZ18011), and Natural Science Research Foundation of the Department of Education of Anhui Province (no. KJ2020A0789).

\section{References}

[1] L. Wang, Study on the Effect of Design on the Quality of Traditional Chinese Medicine, Zhejiang University, Hangzhou, China, 2015.
[2] S. Mehtap and T. Sevgi, "Development and in-vitro evaluation of $\mathrm{pH}$-independent release matrix tablet of weakly acidic drug valsartan using quality by design (QbD) tools," Drug Development and Industrial Pharmacy, vol. 12, no. 44, pp. 19051917, 2018.

[3] Y. Xu, M. Xie, Y. Liang, W. Zhang, X. Cao, and T. Liu, "Optimized preparation of Chuanminshen violaceum buccal tablets based on QbD," Chinese Journal of Experimental Traditional Medical Formulae, vol. 24, no. 17, pp. 14-19, 2018.

[4] L. Deng, C. Chang, Y. Wang et al., "Establishment of safflower extract concentrating process and physical parameter model based on QbD," Chinese Traditional Medicine Journal, vol. 45, no. 19, pp. 4633-4642, 2020.

[5] W. Jamshed and K. S. Nisarl, "Computational single-phase comparative study of a Williamson nanofluid in a parabolic trough solar collector via the Keller box method," Internatinal Journal of Energy Research, vol. 45, no. 7, pp. 10636-10718, 2021.

[6] W. Jamshed, S. U. Devi, and K. S. Nisar, "Single phase based study of Ag-Cu/EO Williamson hybrid nanofluid flow over a stretching surface with shape factor," Physica Scripta, vol. 96, no. 6, p. 65202, 2021.

[7] W. Jamshed, E. Karatas Akgül, K. Sooppy Nisar, Esra, and Kottakkaran, "Keller box study for inclined magnetically driven Casson nanofluid over a stretching sheet: single phase model," Physica Scripta, vol. 96, no. 6, p. 65201, 2021.

[8] W. Jamshed, K. S. Nisar, R. J. P. Gowda, R. N. Kumar, and B. C. Prasannakumara, "Radiative heat transfer of second grade nanofluid flow past a porous flat surface: a single-phase mathematical model," Physica Scripta, vol. 96, no. 6, p. 64006, 2021.

[9] P. Li, T. Liu, W. Zhang, Y. Liang, J. Zhang, and B. Li, "Study on preparation and physical fingerprint of Huanghuai tablets based on QbD," Chinese Herbal Medicine, vol. 49, no. 7, pp. 1576-1582, 2018. 
[10] Y. Wang, C. Chang, L. Deng et al., "Study on the preparation technology and physical fingerprint of safflower granules based on the idea that quality is determined by the design," Chinese Herbal Medicine, vol. 50, no. 17, pp. 4123-4130, 2019.

[11] G. Zhou, X. Huang, and F. Xuehua, "Optimization of the preparation of compound Wuhua granules," Chinese Patent Medicine, vol. 41, no. 6, pp. 1389-1391, 2019.

[12] S. Gui, W. Li, Y. Huang, and J. Wang, "Investigation on the prescription and preparation technology of Peiyuan granules," Chinese Experimental Prescription Science, vol. 21, no. 22, pp. 31-3339, 2015.

[13] Y. Diao, J. Ban, Q. Xie et al., "Effects of two preparation processes on the formability of compound Qishu granules," Chinese Patent Medicine, vol. 39, no. 2, pp. 414-417, 2017.

[14] A. Sun, B. Yuan, N. Li et al., "Study on dry granulation technology of kidney-warming and bone-strengthening granules," Chinese Herbal Medicine, vol. 49, no. 3, pp. 13241330, 2018.

[15] Q. Wang, X. Meng, T. Xue, and S. Sun, "Optimization of extraction and preparation of rust-brown Crotalaria granules," Chinese Patent Medicine, 2020, https://kns.cnki.net/ $\mathrm{kcms} /$ detail/31.1368.R.20201111.0922.002.html.

[16] S. Guo, Q. He, H. Guo et al., "Study on the preparation technology of lily granules," Jiangxi Traditional Chinese Medicine, vol. 51, no. 6, pp. 67-69, 2020.

[17] L. Lu, X. Wang, Y. Wang et al., "Selection of adjuvant material for wind-coursing and panting stabilizer granules," Chinese Patent Medicine, vol. 39, no. 4, pp. 731-736, 2017.

[18] H. Yan, C. Zou, and H. Lu, "Study on moisture-proof adjuvant material of Trichosanthes granules," Chinese Patent Medicine, vol. 37, no. 4, pp. 902-905, 2015.

[19] European Pharmacopeia, "Dosage forms monographs," 2013. 